\title{
Global climatology of near-inertial current characteristics from Lagrangian observations
}

\author{
Alexis Chaigneau, ${ }^{1,2}$ Oscar Pizarro, ${ }^{3}$ and Winston Rojas ${ }^{3}$ \\ Received 22 March 2008; revised 6 May 2008; accepted 28 May 2008; published 11 July 2008.
}

[1] Satellite-tracked surface drifter data from 1999-2006 are used to compute global climatology of inertial current characteristics at seasonal scales. The global mean nearinertial current amplitude at $15 \mathrm{~m}$ depth is $\sim 10 \mathrm{~cm} \mathrm{~s}^{-1}$ corresponding to mixed-layer inertial energies of $\sim 300 \mathrm{~J} \mathrm{~m}^{-2}$. The Southern Ocean and the western North Pacific and Atlantic oceans are the most energetic in the near-inertial frequency band, whereas weaker inertial activity is observed in the subtropical and eastern boundary regions. In every ocean basin, inertial activity is higher during fall and winter, associated with maximum storms activity and deeper mixed-layers. This study also shows that the mixed-layer model developed by R. T. Pollard and R. C. Millard (1970) and forced by the QSCAT/NCEP blended wind product is too energetic in the tropics and not enough at high latitudes. These discrepancies could question the previous estimates of the wind work to inertial motions based on those simulations. Citation: Chaigneau, A., O. Pizarro, and W. Rojas (2008), Global climatology of near-inertial current characteristics from Lagrangian observations, Geophys. Res. Lett., 35, L13603, doi:10.1029/2008GL034060.

\section{Introduction}

[2] The strength of global overturning circulation is related to the intensity of ocean mixing, which partially results from breaking internal waves. The two possible sources of internal waves in the deep-ocean are tides and wind-stress fluctuations. The global energy flux to the deepocean mixing is of the order of $0.6-0.9$ TW from internal tides and of 1-1.2 TW from wind [Wunsch, 1998; Munk and Wunsch, 1998]. Wind-generated inertial currents are the most energetic and lowest frequency constituent of internal waves [Kunze, 1985]. These highly intermittent circular motions, rotating anticyclonically, are generated in the mixed-layer with intrinsic frequency equal to the planetary vorticity $f$. However, since inertial waves are constrained to propagate downward and equatorward [Zervakis and Levine, 1995; Chiswell, 2003], their intrinsic frequencies tend to become superinertial. The observed mixed-layer oscillations are thus a combination of locally wind-forced motions and remotely generated waves. Additional effects, such as the relative vorticity of the large-scale circulation or eddies, can also modify the effective frequency of the inertial waves [Kunze, 1985].

\footnotetext{
${ }^{1}$ IRD, LOCEAN, Université P. et M. Curie, Paris, France.

${ }^{2}$ Also at Instituto del Mar del Perú, Callao, Peru.

${ }^{3}$ Departamento de Geofísica and COPAS, Universidad de Concepción, Concepción, Chile.
}

Copyright 2008 by the American Geophysical Union. 0094-8276/08/2008GL034060
[3] In recent decades, various scientific efforts have been made to globally map and accurately estimate the flux from wind to inertial motions. For example, Alford [2001] estimated a total power input of $0.3 \mathrm{TW}$, driving the mixedlayer slab model developed by Pollard and Millard [1970] with NCEP/NCAR reanalysis winds. Watanabe and Hibiya [2002], using the same model and a wind product compiled from the Japanese Meteorological Agency, estimated a global flux of 0.7 TW. Alford [2003] proposed an improved estimate of around $0.5 \mathrm{TW}$, solving the equations of the slab mixed-layer model in frequency space and extending his analysis poleward of $\pm 50^{\circ}$. Although local comparisons between inertial current observations and that model have shown qualitative agreements [Poulain, 1990; Levine and Zervakis, 1995; Alford, 2001, 2003], the flux estimates are highly sensitive to the wind product and the mixed-layer depth [Jiang et al., 2005; Watanabe and Hibiya, 2002]. Also, the slab-model does not include dissipation mechanisms on short timescales, which drastically overestimates inertial current amplitudes and associated mixed-layer kinetic energy [Plueddemann and Farrar, 2006]. Finally, this model does not take into account the inertial wave propagation from higher latitudes, the advection of inertial energy by large-scale flows or the impact of vorticity and mesoscale activity on the inertial current field.

[4] A global climatology from in-situ measurements is necessary as a benchmark for simulations used to estimate the energy flux from wind to inertial motions. Among the existing oceanographic platforms, satellite-tracked drifters are ideally suited for investigating high frequency dynamics such as tides or inertial oscillations [Poulain, 1990] and also cover a large area of the World Ocean. The main objective of this study is, thus, to use an extensive dataset of driftingbuoy trajectories to compute global climatology of nearinertial current characteristics at seasonal scales.

\section{Data, Model and Methods}

[5] As part of the World Ocean Circulation Experiment Surface Velocity Program, more than 8500 near-surface satellite-tracked drifter trajectories with drogues attached at $15 \mathrm{~m}$ depth are available from July 1999 to December 2006. The raw drifter locations, irregularly distributed in time, are distributed by the Atlantic Oceanographic and Meteorological Laboratory (Miami, USA) along with quality flags. After some data processing the trajectories are interpolated at 3-hour intervals and velocity components are computed (see Text $\mathrm{S}^{1}$ for further details). The Extended Complex Demodulation Technique (ECD) [Poulain, 1990; Emery and Thomson, 1997], applied to velocity vectors of

\footnotetext{
${ }^{1}$ Auxiliary materials are available in the HTML. doi:10.1029/ 2008GL034060.
} 

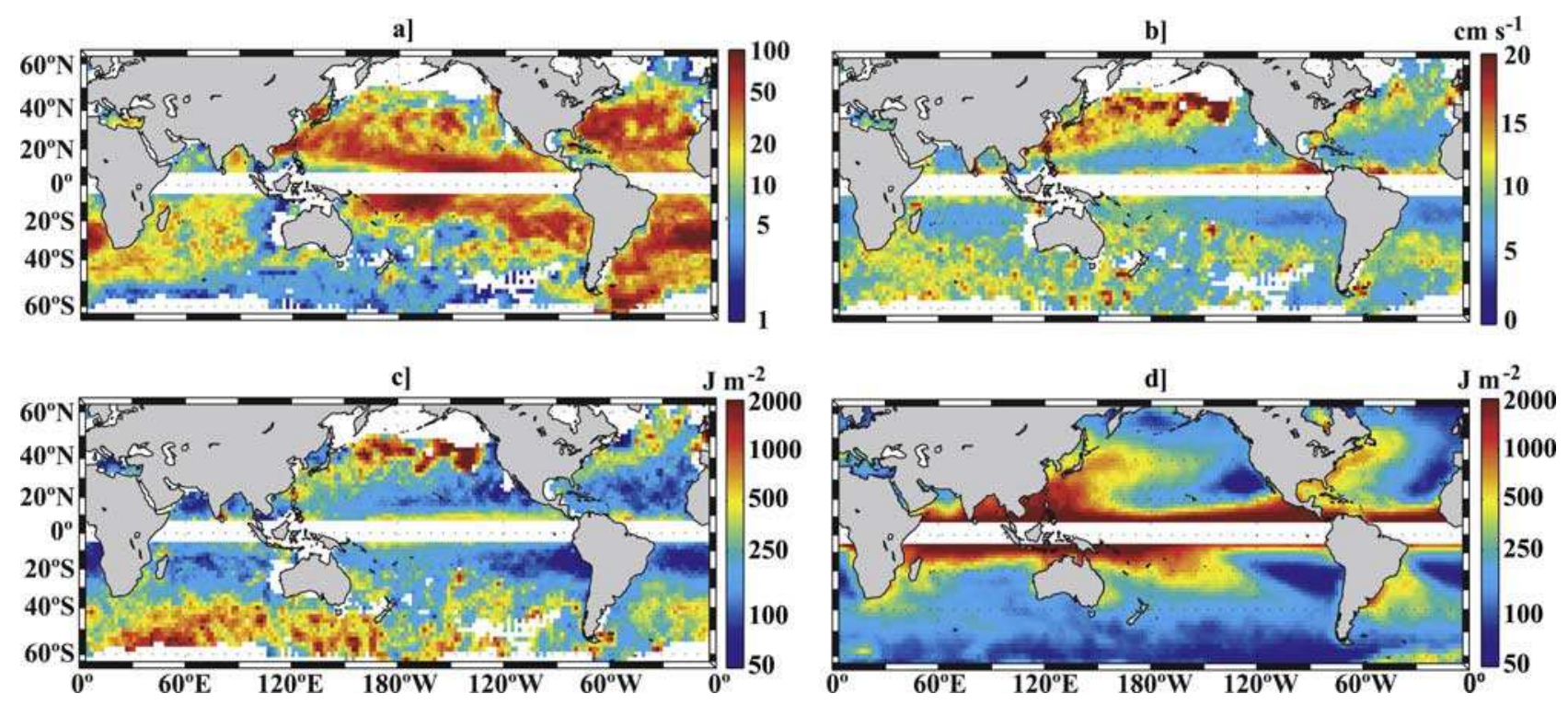

Figure 1. Distribution of mean inertial current characteristics computed (a)-(c) from surface drifters and (d) from a simple mixed-layer slab model. (top) Number of independent observations (Figure 1a) and inertial current amplitudes (Figure 1b). (bottom) Mixed-layer energy related to inertial currents using drifters (Figure 1c) and simulation (Figure 1d) respectively.

record lengths two times the local inertial period $T_{i}$, is then used to estimate the near-inertial amplitude in the frequency band of $0.6 f-1.4 f$ (see Text S1). The retained inertial amplitude and frequency correspond to the maximum explained variance. Over the global ocean, the retained near-inertial frequency shows a Gaussian distribution with a mean value of $f$ and a standard deviation of $0.11 f$. Finally, the bootstrap method [Emery and Thomson, 1997], described in Text $\mathrm{S} 1$, is used to test the significance of the computed inertial amplitudes. Only significant values at a $95 \%$ confidence level are considered, which removes $15 \%$ of the $\sim 5$ millions original estimates.

[6] Assuming that the inertial current amplitude $\left(\left|U_{I}\right|\right)$ is homogeneous in the mixed layer, the inertial horizontal kinetic energy ( $H K E$ ) trapped in the mixed-layer is defined as $H K E=0.5 \rho H\left|U_{I}\right|^{2}$, where $\rho$ is the seawater density in the mixed layer of depth $H$. The density is computed from the monthly climatology of the World Ocean Atlas 2001 [Conkright et al., 2002], assuming that $\rho$ is constant over the mixed layer and equal to its value at $10 \mathrm{~m}$ depth. The mixed layer depth (MLD) is estimated from the monthly climatology of De Boyer Montégut et al. [2004] (hereinafter referred to as DBM04). Both $\rho$ and $H$ are interpolated to the position and time of $\left|U_{I}\right|$ estimates.

[7] The values of $\left|U_{I}\right|$ and $H K E$, irregularly distributed in space and time, are then binned into 3-month seasonal boxes of $2^{\circ}$ latitude by $2^{\circ}$ longitude. As their distributions are not Gaussian the data are gridded using the median value. In the equatorial band $\left(5^{\circ} \mathrm{S}-5^{\circ} \mathrm{N}\right)$, where $f$ tends to zero, inertial characteristics estimates are not considered. Finally, to partially overcome the noisy nature of the observations, we apply a slight smoothing that uses $50 \%$ self-weight and $50 \%$ adjacent weight from the neighboring gridded values as used by DBM04.

[8] The results obtained from Lagrangian observations are compared with a mixed-layer slab model whose equations are described by Pollard and Millard [1970] and
Alford [2001] and are not presented here. Assuming that the wind-stress $\tau$ is uniformly distributed over the mixedlayer, the only natural frequency possible for the system is $f$. To model the decay of inertial oscillations by the radiation out of the mixed-layer, a damping term is introduced and parameterized by a damping coefficient $r$. Our simulation uses a constant density of $1025 \mathrm{~kg} \mathrm{~m}^{-3}$, a varying $H$ interpolated from the atlas of DBM04, and an $r$ varying with latitude $(r / f=0.15)$ as recommended by Alford [2001]. The model is forced by the high-resolution (6-hourly and $0.5^{\circ} \times 0.5^{\circ}$ ) QSCAT/NCEP blended wind product (http:// dss.ucar.edu/datasets/ds744.4/) over the July 1999-June 2006 period. Both $H$ and $\tau$ are linearly interpolated onto one-hour time steps and at the same $0.5^{\circ} \times 0.5^{\circ}$ spatial grid.

\section{Results}

\subsection{Integral Timescale of Near-Inertial Currents and Independent Observations}

[9] An estimation of the time over which inertial currents are auto-correlated is given by the Lagrangian integral timescale $T_{L}$ :

$$
T_{L}=\frac{1}{\overline{R(0)}} \int_{0}^{\infty} \overline{R(\tau)} \cdot d \tau
$$

where $R$ are the Lagrangian autocorrelation functions of the inertial current amplitudes and overbars denote ensemble averages. In practice, $R$ are integrated to the first zero crossing and $T_{L}$ can be then considered as upper limits of the true scales.

[10] The mean Lagrangian autocovariance functions $R$ were computed for each drifter trajectory segment remaining more than $30 \times T_{i}$ in a $2^{\circ}$ latitude band, where $T_{i}$ is the centered inertial period of the given latitude band. The resulting integral timescales, computed from more than 2650 segments assumed to be independent, are lower than 
Table 1. Mean Inertial Current Characteristics (Amplitude, Radius, Energy) in the Mixed-Layer of Every Ocean Basin, Obtained From Satellite-Tracked Drifters ${ }^{\mathrm{a}}$

\begin{tabular}{|c|c|c|c|c|c|c|c|c|c|}
\hline & $\begin{array}{l}\text { Northern } \\
\text { Indian }\end{array}$ & $\begin{array}{l}\text { Southern } \\
\text { Indian }\end{array}$ & $\begin{array}{l}\text { North } \\
\text { Pacific }\end{array}$ & $\begin{array}{l}\text { South } \\
\text { Pacific }\end{array}$ & $\begin{array}{c}\text { North } \\
\text { Atlantic }\end{array}$ & $\begin{array}{c}\text { South } \\
\text { Atlantic }\end{array}$ & $\begin{array}{c}\text { Northern } \\
\text { Hemisphere }\end{array}$ & $\begin{array}{l}\text { Southern } \\
\text { Hemisphere }\end{array}$ & Global \\
\hline Area $\left(10^{7} \mathrm{~km}^{2}\right)$ & 1.5 & 4.8 & 8.2 & 7.8 & 3.4 & 3.4 & 13.5 & 16.0 & 29.5 \\
\hline $\mathrm{N}^{*}$ & 1804 & 12353 & 41056 & 36720 & 23009 & 28937 & 66376 & 77995 & 144371 \\
\hline$\left|U_{I}\right|\left(\mathrm{cm} \mathrm{s}^{-1}\right)$ & 10.5 & 9.9 & 11.5 & 9.1 & 9.7 & 8.8 & 10.8 & 9.3 & 9.9 \\
\hline Radius (km) & 29.7 & 13.4 & 18.7 & 12.9 & 13.8 & 10.0 & 17.8 & 12.3 & 14.6 \\
\hline$H K E\left(\mathrm{~J} \mathrm{~m}^{-2}\right)$ & 262.5 & 322.0 & 347.9 & 265.2 & 230.9 & 236.5 & 302.1 & 274.4 & 286.0 \\
\hline$H K E \times$ Area $\left(10^{16} \mathrm{~J}\right)$ & 0.39 & 1.55 & 2.85 & 2.07 & 0.79 & 0.80 & 4.08 & 4.39 & 8.44 \\
\hline
\end{tabular}

${ }^{a}$ All means are computed over $50^{\circ} \mathrm{S}-50^{\circ} \mathrm{N}$. $\mathrm{N}^{*}$ corresponds to the number of independent observations.

$20 \mathrm{~h}$ poleward of $\pm 50^{\circ}$ and increase equatorward to $\sim 110 \mathrm{~h}$ at around $\pm 5^{\circ}$ (Figure S1). However, the integral timescales normalized by $T_{i}$ are rather independent of latitude, with values in the range of $1.1-1.6 \times T_{i}$. Over the world ocean, the mean integral timescale of inertial current amplitudes is $T_{L}=(1.3 \pm 0.2) \times T_{i}$.

[11] Each Lagrangian observation separated by more than two times the temporal scale $T_{L}$ can be considered independent [Flierl and McWilliams, 1977]. Using a large decorrelation timescale of $3 \times T_{i}$, the geographical distribution of the number of independent observations $N^{*}$ was computed on a $2^{\circ} \times 2^{\circ}$ resolution (Figure 1a). A greater number of independent data are observed in the entire Atlantic Ocean and in the Pacific Ocean north of $20^{\circ} \mathrm{S}$, but also in the Indian Ocean west of $100^{\circ} \mathrm{E}$. In contrast, fewer independent data are located in the extreme North Atlantic and in the Indian and Pacific sectors of the Southern Ocean. In these regions, the number of drifter trajectories is sparse and $T_{i}$ is short, reducing the number of trajectory segments satisfying the criterion $\Delta \mathrm{t}<T_{i} / 4$ required to compute $\left|U_{i}\right|$ (see Text S1). North of $50^{\circ} \mathrm{N}$ in the Pacific Ocean, the buoys have a relatively large duty cycle also preventing the computation of the ECD (see Text S1).

\subsection{Mean Inertial Current Characteristics}

[12] Mean mixed layer inertial current amplitudes vary between a few $\mathrm{cm} \mathrm{s}^{-1}$ to $\sim 25 \mathrm{~cm} \mathrm{~s}^{-1}$ (Figure 1b). The less energetic currents $\left(\left|U_{I}\right|<10 \mathrm{~cm} \mathrm{~s}^{-1}\right)$ are observed in both hemispheres in the suptropical latitude band between $15^{\circ}$ and $30^{\circ}$, and more particularly in the eastern boundary regions, where both the wind variance and the inertial component of the wind are weak (not shown). The largest, western-enhanced, inertial currents are found between $30^{\circ}-$ $50^{\circ} \mathrm{N}$ across the Pacific and Atlantic oceans and are principally forced by the intermittent passage of traveling midlatitude storms [Chang et al., 2002]. Strong inertial activity is also found in regions affected by tropical cyclones, such as at around $\pm 20^{\circ}$ in the western Pacific or in the tropical Atlantic [Gray, 1985]. The patch of high inertial activity located in the eastern tropical Pacific is probably related to the intermittent wind jets of Central America [Chelton et al., 2000]. In the Southern Hemisphere relatively strong inertial activity is observed around the circumpolar belt in agreement with the storm-track activity which is remarkably persistent throughout the year in both location and intensity [Trenberth, 1991]. Furthermore, the strongest (or weakest) inertial velocities are observed in the Indian (or South Pacific) Ocean, consistent with the strongest (or weakest) storm activity [Trenberth, 1991].

[13] A spatial map of $H K E$ shows a similar distribution (Figure 1c), except in the Southern Ocean or in the extreme North Atlantic. In these regions, $U_{i}$ is of the order of $10-12 \mathrm{~cm} \mathrm{~s}^{-1}$ but $H K E$ can reach values of $1000-3000 \mathrm{~J} \mathrm{~m}^{-2}$ associated with wintertime deep convection which extends the mixed-layer to $300-500 \mathrm{~m}$ depth (DBM04). The HKE distribution is rather badly reproduced by the wind-forced model (Figure 1d). In the
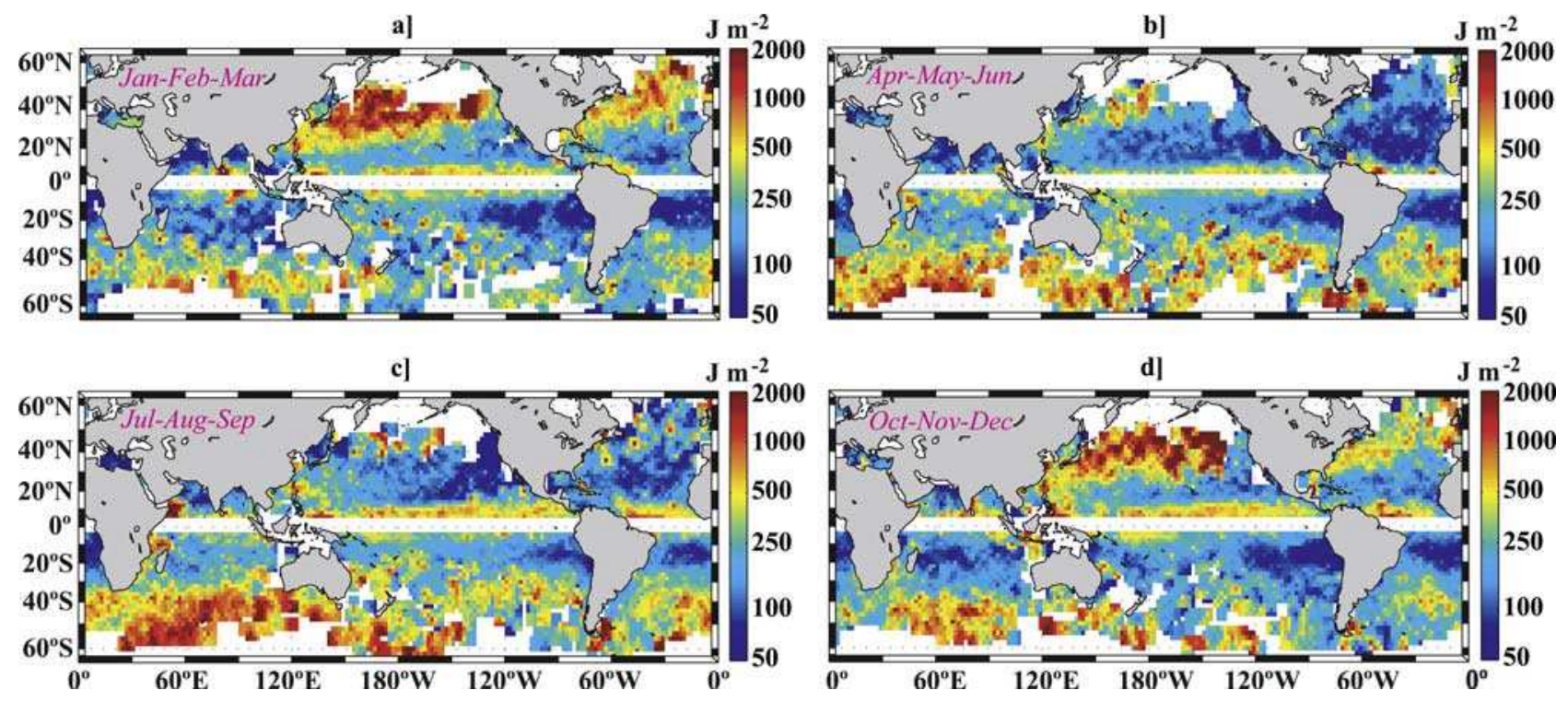

Figure 2. Seasonal variation of inertial mixed-layer energy computed from satellite-tracked drifter trajectories. 

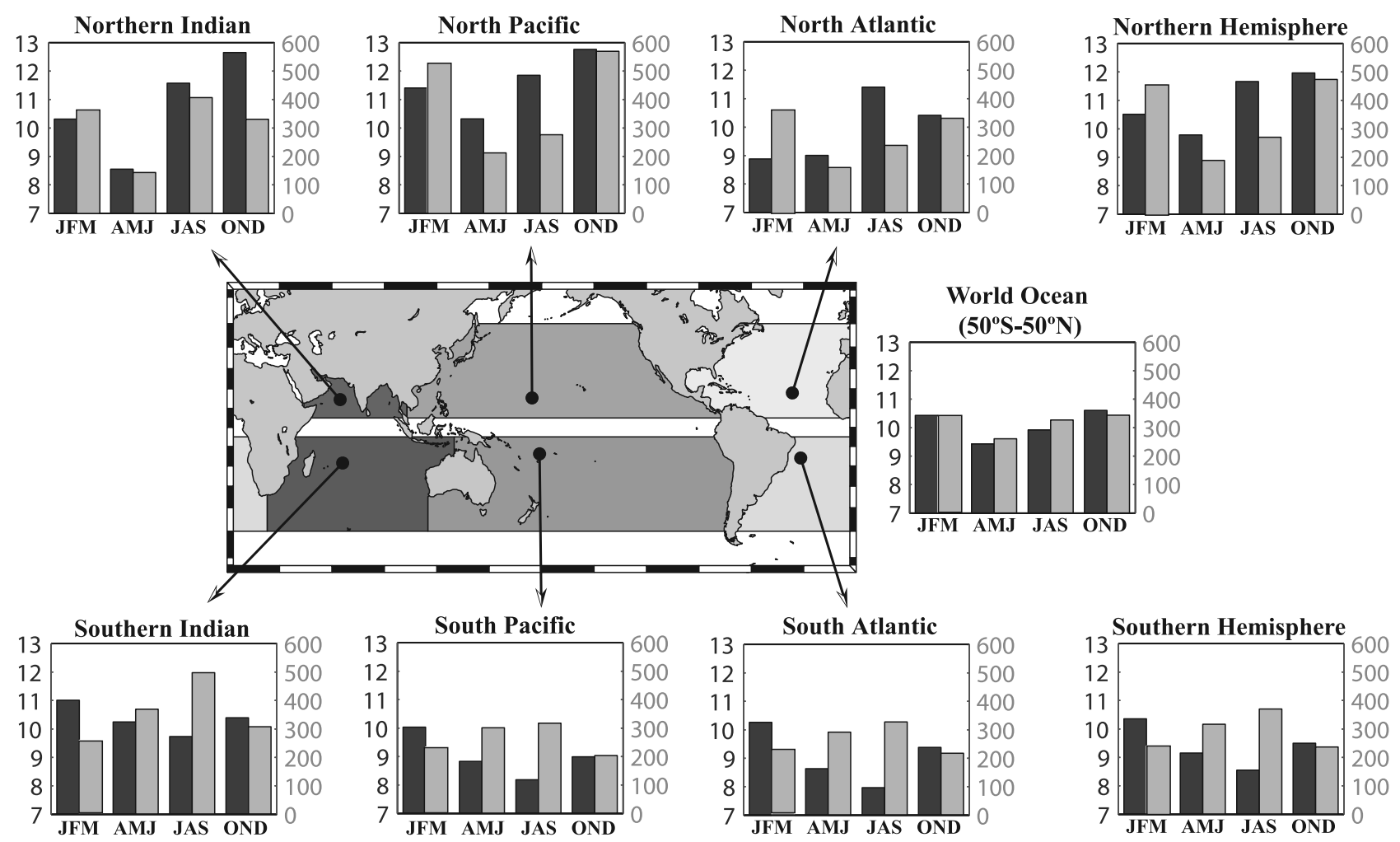

Figure 3. The seasonal cycle of inertial current amplitude (black bars, left scales, in $\mathrm{cm} \mathrm{s}^{-1}$ ) and mixed-layer energy (gray bars, right scales, in $\mathrm{J} \mathrm{m}^{-2}$ ) in every ocean basin, both hemispheres, and in the World Ocean.

simulation, unrealistic high values of $H K E$ are found in the tropical band and relatively weak values in high latitude regions. Also, the strong inertial activity centered at $50^{\circ} \mathrm{N}$ across the entire Pacific Ocean is not simulated by the model. These discrepancies also contrast with the simulation of Alford [2001, 2003] and Watanabe and Hibiya [2002] probably due to the different wind products used in these studies [Jiang et al., 2005].

[14] On average, inertial current amplitudes are of order of $10 \mathrm{~cm} \mathrm{~s}^{-1}$ in every ocean basin and slightly stronger by $1-2$ $\mathrm{cm} \mathrm{s}^{-1}$ in the Northern Hemisphere (Table 1). This corresponds to circular motions having radii of $10-30 \mathrm{~km}$. Mean values of $H K E$ vary from a minimum of $\sim 230 \mathrm{~J} \mathrm{~m}^{-2}$ in the Atlantic Ocean to a maximum of $\sim 350 \mathrm{~J} \mathrm{~m}^{-2}$ in the North Pacific. Over the World Ocean between $50^{\circ} \mathrm{S}$ and $50^{\circ} \mathrm{N}$, inertial currents have mean amplitudes of $\sim 10 \mathrm{~cm} \mathrm{~s}^{-1}$, spatial scales of $10 \mathrm{~km}$ and a mixed-layer energy of $\sim 300 \mathrm{~J} \mathrm{~m}^{-2}$. The total energy available in the mixedlayer of the World Ocean is estimated as $8.4 \times 10^{16} \mathrm{~J}$.

\subsection{Seasonal Cycle of Inertial Current Characteristics}

[15] The distribution of $H K E$ shows important seasonal variability (Figure 2). Maximum values are reached during the respective autumn and winter seasons of both hemispheres. During these seasons, the MLD are deeper by a factor 2-4 (DBM04), and $\left|U_{I}\right|$ is increased by a factor 2 across the western North Atlantic and Pacific due to the passage of mid-latitude winter storms, resulting in a strong increase of $H K E$.

[16] Figure 3 shows the seasonal variation of $\left|U_{I}\right|$ and $H K E$ in the distinct ocean basins and hemispheres. In the
Northern Hemisphere, $\left|U_{I}\right|$ varies seasonally by $\pm 2 \mathrm{~cm} \mathrm{~s}^{-1}$ around its mean value of $\sim 10 \mathrm{~cm} \mathrm{~s}^{-1}$ with minimum values observed in the North Atlantic. Typical HKE values of $100-200 \mathrm{~J} \mathrm{~m}^{-2}$ (or 500-600 $\mathrm{J} \mathrm{m}^{-2}$ ) are observed in summer (or winter). Minimum seasonal cycle amplitudes are observed in the North Atlantic whereas the Northern Indian basin exhibits the strongest seasonal variability, probably associated with monsoon wind regimes and typhoon activity [Alford and Gregg, 2001]. In the Southern Hemisphere, mean values and seasonal variability are weaker, except in the Southern Indian basin, characterized by large fluxes of wind to inertial motions [Alford, 2001]. On average, over the Southern Hemisphere, inertial currents are approximately $8-10 \mathrm{~cm} \mathrm{~s}^{-1}$ year-round and $H K E$ varies between 200 and $400 \mathrm{~J} \mathrm{~m}^{-2}$. The total amount of energy integrated over the global ocean varies by $25 \%$ between a minimum of $7.7 \times 10^{16} \mathrm{~J}$ in April-May-June to $10.1 \times 10^{16} \mathrm{~J}$ in October-November-December.

\section{Conclusion}

[17] This study, based on an important surface drifter dataset from 1999-2006, provides a global climatology of inertial current characteristics at seasonal scales. Inertial motions have a typical radius of $10-30 \mathrm{~km}$ and a temporal scale of $1.3 \times T_{i}$. In both hemispheres, inertial amplitude is of $\sim 10 \mathrm{~cm} \mathrm{~s}^{-1}$ and inertial energy of $200-400 \mathrm{~J} \mathrm{~m}^{-2}$, with higher values across the western North Pacific and Atlantic and in the Southern Ocean, particularly during fall and winter, when both the storms activity is at a maximum and mixed-layers are deeper. 
[18] As presented in Figure S2 and Text S2, a numerical simulation was performed to evaluate the errors on the inertial current characteristics $\left(\left|U_{I}\right|\right.$ and $\left.H K E\right)$, using synthetic trajectories calculated as the sum of a constant background and a steady-state inertial velocity. The four control parameters in this simulation are the background velocity, the inertial current amplitude, the inertial period, and the position errors. The errors on the inertial current characteristics principally depend on the latitude and the corresponding local $T_{i}$, and weakly depend on the other parameters. The computed errors, increasing with latitude, always indicate an underestimation of the true inertial characteristics, in a range of $5-35 \%$ for $\left|U_{I}\right|$ and of $10-$ $55 \%$ for $H K E$. The main reasons are that velocity vectors are computed from positions at 3 hour intervals which inevitably underestimate the speed of inertial velocity and that the ECD method assumes steady inertial currents during $2 \times \mathrm{T}_{\mathrm{i}}$.

[19] However, the mean inertial current amplitudes obtained in this study are in good agreement with localized historical measurements made in the mixed-layer from various types of instruments (see Table S1). A special comparison with global statistics, obtained from ARGO buoys dataset [Park et al., 2005], indicates that our estimates are weaker by $0-2 \mathrm{~cm} \mathrm{~s}^{-1}$ for $\left|U_{I}\right|$ and by a factor $\sim 2$ for $H K E$, approximately in the range of the errors discussed above. These discrepancies can also be explained as follows: 1) Park et al. [2005] only used $\sim 15000$ estimates, much less than the $\sim 4$ millions observations used in this study; 2) to estimate the HKE they determined both $\rho$ and the MLD directly from ARGO profiles; 3 ) their estimates are based on a distinct method using trajectory segments of length $0.7 \times T_{i}$. Applying their methodology to a regional surface-drifter dataset, Park et al. [2004] also observed smaller inertial amplitudes and attributed the difference to the vertical shear of inertial currents because the drifters followed the current at $15 \mathrm{~m}$ whereas the ARGO floats drifted at the surface.

[20] The climatology computed from Lagrangian surface drifter trajectories provides useful metrics for validating inertial current characteristics in numerical models. On average over the World Ocean, the mixed-layer slab model developed by Pollard and Millard [1970] slightly overestimates the inertial activity with a mean $\left|U_{I}\right|$ of $\sim 12 \mathrm{~cm} \mathrm{~s}^{-1}$ and $H K E$ of $600 \mathrm{~J} \mathrm{~m}^{-2}$. However, the spatial distributions of these fields show much more discrepancies from the observations. For example, the response of the model to the NCEP/QSCAT blended wind-product shows higher HKE in the tropics [Jiang et al., 2005] and weaker values in the high latitude regions. The $H K E$ accumulation is also probably due to the lack of damping mechanism on a short timescale in the model [Plueddemann and Farrar, 2006]. Our results bring into question previous estimates of the wind work to inertial motions based on these simulations.

[21] Acknowledgments. The raw drifter data set was generously provided by M. Pazos and J. Redman from AOML. OP appreciates support from FONDECIT 1040986 and FONDAP COPAS. WR was partly funded by the PCCC project from the Agence Nationale de la Recherche, France.

\section{References}

Alford, M. H. (2001), Internal swell generation: The spatial distribution of energy flux from the wind to mixed layer near-inertial motions, J. Phys. Oceanogr., 31, 2359-2368.

Alford, M. H. (2003), Improved global maps and 54-year history of wind work on ocean inertial motions, Geophys. Res. Lett., 30(8), 1424, doi:10.1029/2002GL016614.

Alford, M. H., and M. C. Gregg (2001), Near inertial mixing: Modulation of shear, strain and microstructure at low latitude, J. Geophys. Res, 106, $16,947-16,968$

Chang, E. K. M., S. Lee, and K. L. Swanson (2002), Storm track dynamics, J. Clim., 15, 2163-2183.

Chelton, D. B., M. H. Freilich, and S. K. Esbensen (2000), Satellite observations of the wind jets off the Pacific coast of Central America. Part I: Case studies and statistical characteristics, Mon. Weather Rev, $128,1993-2018$.

Chiswell, S. M. (2003), Deep equatorward propagation of inertial oscillations, Geophys. Res. Lett., 30(10), 1533, doi:10.1029/2003GL017057.

Conkright, M. E., R. A. Locarnini, H. E. Garcia, T. D. O'Brien, T. P. Boyer, C. Stephens, and J. I. Antonov (2002), World Ocean Atlas 2001: Objective Analyses, Data Statistics, and Figures [CD-ROM], NOAA, Silver Spring, Md.

De Boyer Montégut, C., G. Madec, A. S. Fischer, A. Lazar, and D. Iudicone (2004), Mixed layer depth over the global ocean: An examination of profile data and a profile-based climatology, J. Geophys. Res., 109, C12003, doi:10.1029/2004JC002378

Emery, W. J. and R. E. Thomson (1997), Data Analysis Methods in Physical Oceanography, Pergamon, Oxford, U. K.

Flierl, G. R., and J. C. McWilliams (1977), On the sampling requirements for measuring moments of eddy variability, J. Mar. Res., 35, 797-820.

Gray, W. M. (1985), Tropical cyclone global climatology, vol. I, Tech. Doc. WMO/TD 72, 319 pp., World Meteorol. Org., Geneva, Switzerland.

Kunze, E. (1985), Near inertial wave propagation in geostrophic shear, J. Phys. Oceanogr., 15, 544-565.

Jiang, J., Y. Lu, and W. Perrie (2005), Estimating the energy flux from the wind to ocean inertial motions: The sensitivity to surface wind fields, Geophys. Res. Lett., 32, L15610, doi:10.1029/2005GL023289.

Levine, M. D., and V. Zervakis (1995), Near-inertial wave propagation into the pycnocline during ocean storms: Observations and model comparison, J. Phys. Oceanogr., 25, 2890-2908.

Munk, W., and C. Wunsch (1998), Abyssal recipes II: Energetics of tidal and wind mixing, Deep Sea Res., Part I, 45, 1977-2010.

Park, J. J., K. Kim, and W. R. Crawford (2004), Inertial currents estimated from surface trajectories of ARGO floats, Geophys. Res. Lett., 31, L13307, doi:10.1029/2004GL020191.

Park, J. J., K. Kim, and B. A. King (2005), Global statistics of inertial motions, Geophys. Res. Lett., 32, L14612, doi:10.1029/2005GL023258.

Plueddemann, A. J., and J. T. Farrar (2006), Observations and models of the energy flux from the wind to mixed-layer inertial currents, Deep Sea Res., Part II, 53, 5-30.

Pollard, R. T., and R. C. Millard Jr. (1970), Comparison between observed and simulated wind-generated inertial oscillations, Deep Sea Res., 17, $813-821$

Poulain, P.-M. (1990), Near-inertial and diurnal motions in the trajectories of mixed layer drifters, J. Mar. Res., 48, 793-823.

Trenberth, K. E. (1991), Storm tracks activity in the Southern Hemisphere, J. Atmos. Sci., 48, 2159-2178.

Watanabe, M., and T. Hibiya (2002), Global estimates of the wind-induced energy flux to inertial motions in the surface mixed layer, Geophys. Res. Lett., 29(8), 1239, doi:10.1029/2001GL014422.

Wunsch, C. (1998), The work done by the wind on the oceanic general circulation, J. Phys. Oceanogr., 28, 2332-2340.

Zervakis, V., and M. D. Levine (1995), Near-inertial propagation from the mixed-layer: Theoretical considerations, J. Phys. Oceanogr., 25, $2872-2889$.

A. Chaigneau, IRD, LOCEAN, Université Pierre et Marie Curie, 4 place Jussieu, F-75252 Paris CEDEX 05, France. (alexis.chaigneau@ird.fr)

O. Pizarro and W. Rojas, Departamento de Geofísica, Universidad de Concepción, Concepción 3, Chile. 